\title{
ANDRAGOGY'S DETECTIVES: A CRITIQUE OF THE PRESENT AND A PROPOSAL FOR THE FUTURE
}

JOHN R. RACHAL

University of Southern Mississippi

\begin{abstract}
The empirical literature examining the efficacy of andragogy remains, after over three decades, both inconclusive and beset by considerable variability in definition, resulting in differing approaches to andragogy's implementation. This empirical record, residing largely in unread dissertations, is critiqued with a view toward establishing criteria for an operational, researchable, consensus-based definition of Knowles' famous formulation. Seven such criteria are offered. Whether these-or other-criteria reach a kind of critical mass of agreement for future investigators is open for further discussion. But the current muddle of definitions and implementations has effectually stalled research. Unless that discussion reaches some approximate consensus, adult education's most familiar and most debated theory will remain a fragmented article of faith at best, a fond illusion at worst.
\end{abstract}

The European origins of the term andragogy are well known to most students of adult education. Although the German Alexander Kapp is credited with the first usage of the term in 1833, Dusan Savicevic (1999) has noted its Greek and Roman antecedents as well as the rich European tradition of the word itself in the 19th and early 20th centuries. In a 1926 Workers' Education article, Lindeman (1926a) and then a year later Lindeman and Anderson (1927) borrowed from this tradition in two fugitive American uses of the term (Stewart, 1987). But Lindeman did not develop his themes around andragogy, choosing instead adult education-itself a term just coming into vogue. Malcolm Knowles, the best-known modern interpreter and advocate of andragogy as both a word and a philosophically-rooted methodology, did not inherit the word from Lindeman, whom he knew and thought of as an early mentor, but from Savicevic of Yugoslavia in the late 1960s (Knowles, 1984). Knowles' development of the concept was grounded in several assumptions ${ }^{2}$ he made about the nature of the adult learner, and it evolved in a different direction from the European use. At least in the English-language literature, his view has

JOHN R. RACHAL is a professor of adult education at the University of Southern Mississippi, Hattiesburg (e-mail: john.rachal@usm.edu). 
achieved a certain primacy and thereby spawned a lively host of critics and apologists.

Much of this attention is attributable to andragogy's preeminence as the most persistent practice-based, instructional methods issue in adult education since Knowles reintroduced the term in 1968 (Knowles, 1968). Despite the use of the word science in Knowles' elusive definition of andragogy as "the art and science of helping adults learn" (1980, p. 42), much of the debate has swirled around the philosophical underpinnings of the concept rather than its empirical efficacy. Due to the elasticity of meanings of andragogy and the consequent variability of interpretations, empirical examinations of andragogy-its science, one might sayhave tended to be inconclusive, contradictory, and few. This fate is likely to persist as long as an operational, researchable definition of andragogy eludes researchers.

If Knowles was serious about the science component of andragogy-and his choice not to substantially modify his definition over three decades suggests that he was-then subsequent researchers should be expected and indeed have the obligation to examine the validity of a theory which has had such a pervasive influence in the field of adult education. The extensive anecdotal, expository, and polemical writing on the subject (Davenport \& Davenport, 1985; Knowles, 1984) has tended to obscure empirical investigations, and most of the latter have been dissertations which rarely reach a wide audience. Such investigations are further impeded by the absence of clear meaning as to what procedures constitute andragogical practice. Knowles himself implemented andragogy through the use of a learning contract, in which learning objectives, strategies and resources, evidence of achievement, and criteria and means for evaluation are all collaboratively determined by the learner and a facilitator. By contrast, investigators have examined, for example, discussion format, individualized programmed learning, collaborative development of objectives, and variations on contract learning-all presumed to be andragogy. A third and seemingly insurmountable obstacle to empirical studies of andragogy's effectiveness, at least in terms of knowledge acquisition, is the catch-22 inherent within the very concept of Knowlesian andragogy: "effectiveness" is largely determined by learner achievement which is often measured by tests and grades; but for Knowles, tests and grades are anathema to the very idea of andragogy.

Merriam and Caffarella (1991) have observed that andragogy is "the best known 'theory' of adult learning," but that "it has also caused more controversy, philosophical debate, and critical analysis than any other concept/theory/model proposed thus far" (pp. 249-250). Yet they note that only "a few studies have attempted" empirical investigation (p. 251). Similarly, Davenport and Davenport (1985, p. 158) called over 15 years ago for "the andragogy debate to move to a higher level." Similarly, Cross's (1981) question seems as relevant today as it did 20 years ago: "Whether andragogy can serve as the unifying theory of adult education remains to be seen. . . . Does andragogy lead to researchable questions that will advance knowledge in adult education?" (pp. 227-228). Finally, Pratt (1993) has noted that the empirical questions are still unanswered: "We cannot say, with any confidence, 
that andragogy has been tested and found to be, as so many have hoped, either the basis for a theory of adult learning or a unifying concept for adult education" (p. 21).

Despite such a chorus of laments, some empirical explorations have been done, mostly in unread dissertations. Cavils might be raised that most of these studies, discussion of which follows, are fading products of the mid-1980s through the mid-1990s. But the absence of empirical studies over the last five years (save one: Hornor, 2001) may well reflect not disinterest but rather the possibility that andragogy efficacy studies have essentially stalled due to the continued absence of an operational definition. One might also object that the calls for empirical research cited above have also faded. The inference might be that andragogy in general has so fallen from fashion that it holds little more than antiquarian interest. Certainly it is true that andragogy has increasingly had to share the field with an ever-widening expanse of newer theories and approaches to the teaching-learning transaction (Pratt, 1998). Yet the significance of andragogy and Knowles continues to engage us. Perhaps the best evidence for this is buried in the microscopic print of the Social Sciences Citation Index, which reveals that Knowles has garnered more journal citations over the last 6 years than any of the half-dozen of the field's most wellknown and well-published authors, with the one exception of Friere.

The purpose here then is to review some of the existing studies ${ }^{2}$ and their issues and problems with a view toward developing criteria for an operational definition of andragogy suitable for the kind of further scientific investigation that Merriam and Caffarella (1991), Davenport and Davenport (1985), Cross (1981), and Pratt (1993) suggest is needed.

There are a number of reasons such an operational definition tends to be ephemeral. One is that the art of andragogy may be dominant over the science of it. Another is the customization of andragogy that is inevitably required to address the breadth of situational and contextual variables in a given learning situation (e.g., are paper and pencil tests required? Are the learners degree-seekers muddling through a required course or are they participating strictly for personal enrichment? Even if contracts are utilized in the experience, who determines the objectives?). A third reason for the elusiveness is what might be called "paradigm devolution." This coined term suggests that ideals serve as models for desired belief and consequent behavior; but over time the actual practice of the ideal tends to devolve into a pale reflection of the ideal itself-a descent from ideal to ideology. The original proponent of the ideal, its progenitor, is rarely matched by disciples attempting to practice and preserve the ideal themselves. In short, followers tend to degrade (albeit perhaps unintentionally) the ideal that was promulgated by its original proponent. While paradigm devolution may have particular application to politics and religion (for example, from The Communist Manifesto to the Gulag and from the Sermon on the Mount to the Spanish Inquisition), one might also apply it to andragogy. A particular implementation of andragogy may fall short of the idealized view in that, for example, the facilitator lacks the art of andragogy, or one or more of Knowles' assumptions about the adult learner do not fully apply, or the facilitator may think 
she is providing more learner control than in fact she is. Knowles' edited book Andragogy in Action (1984) offers a number of examples of andragogy's implementations that, at best, are elastic variants of andragogy and at worst'seem to violate it altogether. In the hands of the least artful followers, the ideal calcifies and becomes an orthodoxy revered mostly through lip service. And if the paradigm fully devolves, and is left in the hands of its latter-day masqueraders, the implementation not only falls short of the ideal, but can actually repudiate it, contradict it, and corrupt it-yet perversely still carry its name, bask in its glow, and demand the reverence accorded to it.

\section{THE SEARCH FOR EVIDENCE}

A number of these customizations and devolutions occur in the empirical literature on andragogy (see Table 1). A general problem is noncomparability of studies, particularly the wide variance in what the researchers meant by andragogy and thus how they implemented it. Other shortcomings are the result of inherent problems of design. These include: mixing of adults and nonadults; absence of learner control; paper-pencil tests of achievement; and questionable voluntarism of learners.

Relative to the first of these, several studies failed to differentiate adult students from other students within the study. A number of studies examined in situ groups within a college setting but were unable or chose not to isolate the adult or nontraditional students in the treatment and control groups. Anaemena (1986), Clark (1991), Farrar (1991), Langston (1990), and Strawbridge (1995) all illustrate this problem. These studies, all done in college settings, used experimental and control (or comparison) groups, with both groups potentially containing nontraditional students. However, none used a $2 \times 2$ design with one group of nonadults (traditional students) receiving a traditional-type instruction, a second group of nonadults receiving an andragogical-type instruction, a third group of adults receiving a traditional-type instruction, and a fourth group of adults receiving an andragogical-type instruction. Although colleges enroll many adults, the failure or inability to isolate the adults in a setting that is still considered to be primarily aimed at traditional, nonadult students tends to compromise any conclusions about the efficacy of andragogy which, by definition, is aimed at the adult student. By contrast, several studies not in the college setting examined only adult populations: Beder and Carrea (1988), Cartor (1991), Cross (1989), Familoni (1992), Farrar (1991), Madriz (1987), Ogles (1990), Rosenblum and Darkenwald (1983), Saxe (1987), and White (1989).

A second concern is that of learner control. Andragogy's meaning, in the purest Knowlesian sense, advocates learner control (at the very least, substantial input) over not only the objectives but also the learning strategies as well as evaluation procedures. Yet in several of these investigations, instructor control is near absolute, and learner control is negligible. Knowles (1970) refers to the "theological foundation of adult education" as "a faith in the ability of the learner to learn for 


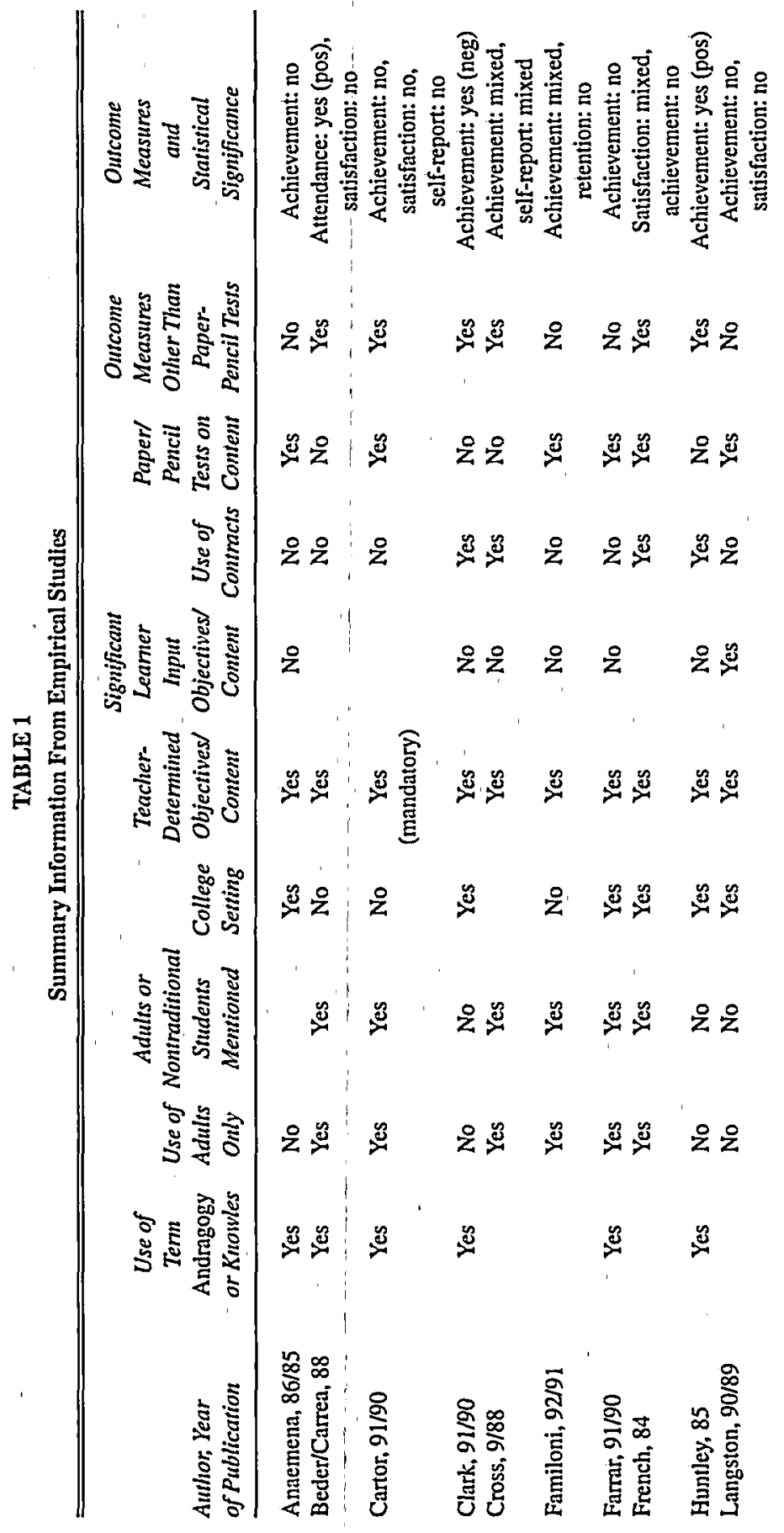




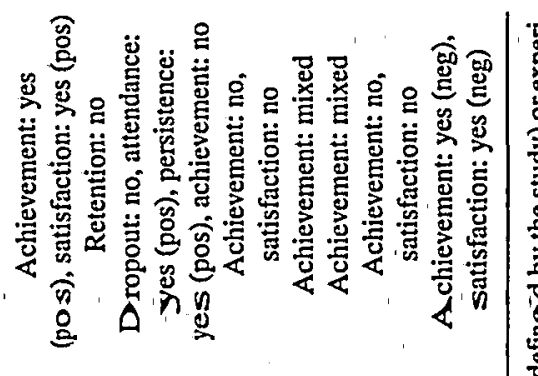

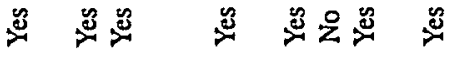

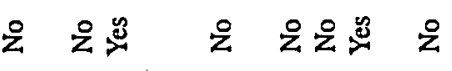

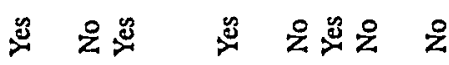

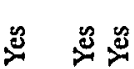

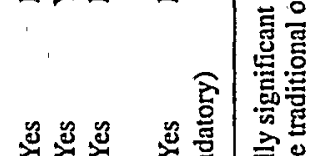

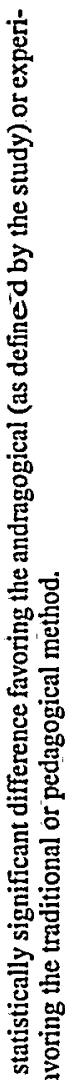

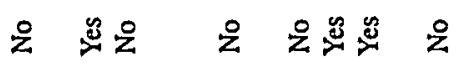

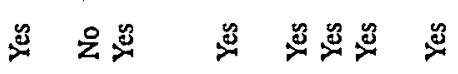

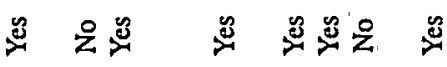

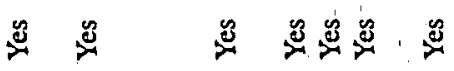

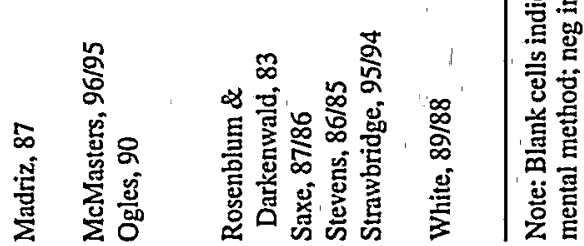


himself," expressed in the radical statement that "the truly artistic teacher of adults perceives the locus of responsibility for learning to be in the learner; he conscientiously suppresses his own compulsion to teach what he knows his students ought to learn in favor of helping his students learn for themselves what they want to learn" (p. 51, emphasis added). Not only do these studies often fall short of that ideal, but Knowles himself was not always able-or willing-to scale such Olympian heights. In a late-1970s second-year seminar-type class with no prescribed content in which this author was a student, Knowles allowed near total freedom in learner determination of objectives. But in his first-year foundations-type class, he clearly intended the class to explore the 18 objectives listed on the syllabus, though class members had a good deal of freedom in selecting those on which to focus as well as how to achieve them. This seems not so much a violation of principle as much as a legitimate accommodation to a situation. Even so, instructor objectives represent a devolution from the andragogical ideal.

Many of the studies critiqued here also had predetermined objectives, and often far less learner freedom in selecting among them, if any. Anaemena (1986), Cartor (1991), Clark (1991), Familoni (1992), Farrar (1991), Madriz (1987), Saxe (1987), Stevens (1986), Strawbridge (1995), and White (1989) all used a relatively prescribed content determined by the instructor though varying degrees of freedom existed in the means of reaching the objectives. Even among those authors using contracts (Clark, 1991; French, 1984; Huntley, 1985; Strawbridge, 1995), many did not allow significant learner freedom in determining objectives, though they may have in the means of achieving those objectives. Indeed, it would be useful in future discussions of learning contracts to distinguish between the learner-determinedobjectives contract and the teacher-determined-objectives contract. Even here there is gray area between the two as contextual factors (certification, grades, the need for a specific content mastery) tend to make learner-objective contracts less common and often infused with considerable teacher input. Ogles (1990, p. 1875), for example, used contracts with adult beginning readers where the contract was "a checklist of tutor-student mutual expectations, student goals, and choice of materials." While learner choice is clearly evident, tutor input on the checklist is equally apparent. Perhaps this is the perfect compromise, but it is not quite the ideal learner control Knowles (1970, p. 51) embraced when he advised that the "truly artistic teacher conscientiously suppresses what he knows his students ought to learn in favor of helping his students learn for themselves what they want to learn."

Among studies not using contracts, what researchers meant by andragogy also varied widely. Anaemena (1986) prepared three lesson plans and well-written programmed instruction sheets, administering lecture-lessons to the pedagogical group while distributing the programmed instruction sheets to the andragogical group to study on their own. Beder and Carrea (1988) recruited a treatment group, a placebo group, and a control group, with the treatment group receiving instruction "designed to facilitate acquisition of andragogically oriented teaching methods" (p. 78), the placebo group receiving "inert" instruction from the participants in 
their areas of content specialty, and the control group neither meeting nor receiving instruction. Cartor (1991, p. 1760) compared "lecture-style training (pedagogy) to participative style training (andragogy)." Familoni (1992, p. 3502) used a "noncollaborative" method with 11 adult female beginning readers one week and a "collaborative" method the second week. Farrar (1991, p. 400) compared groups using "concept mapping," "journal/sketchbooks," and "traditional assignment" in art classes. Langston (1990, p. 3824) compared community college political science students who completed a traditional class project and those who completed a self-directed project that they "designed, completed, and graded" themselves. Rosenblum and Darkenwald (1983, p. 147) had one group of nursing supervisors who "participated in planning their course in supervision," and followed it with a control group of support service supervisors who "completed the course as planned by the experimental group." Madriz (1987) also used a high degree of learner input in planning training activities. Saxe (1987) compared three groups of volunteers learning to read a bank statement using high, moderate, and low levels of peer interaction. Finally White (1989) examined the effectiveness of lecture versus small group discussion in a mandated pesticide recertification program. While all of these studies were more complex than their brief descriptions here suggest, it is quite clear that what they considered to be andragogy, as well as their implementations of it, varied considerably. (For additional information on all cited studies, see Table 1.)

In addition to the considerable variation in the implementation of andragogical methodologies, many of these studies introduced another anti-andragogical element-utilization of paper-pencil tests of content acquisition, a practice not favored by either Lindeman (1926b) or Knowles. For both men, such tests smack of "schooling" and "pedagogy" in its Knowlesian pejorative sense. Thus, we come to the primary Achilles' heel of examining andragogy's effectiveness in terms of content acquisition: andragogy eschews paper-pencil testing, yet that is the most common and presumably easiest form of determining whether the learner has mastered content. Anaemena (1986), Cartor (1991), Familoni (1992), Farrar (1991), French (1984), Madriz (1987), Ogles (1990), Rosenblum and Darkenwald (1983), Saxe (1987), Strawbridge (1995), and White (1989) all employed a paper-pencil test of achievement, although several of these examined additional variables by other means (for example, satisfaction measured by an opinion-type questionnaire, or retention in the program).

By contrast, two studies did not explicitly examine achievement (Beder \& Carrea, 1988; McMasters, 1996), while others examined achievement by more andragogy-friendly means than paper-pencil tests: Clark (1991) examined clinical performance of nurses; Cross (1989, p. 1837) examined "lumbar strength/power, pain perception, and perceived self-control of rehabilitation outcome" of patients; Huntley (1985) recorded the number of bleeding points in an oral-hygiene education program; and Stevens (1986), like Huntley also at Kansas State and also examining an oral-hygiene program, examined brushing and flossing behaviors. The twin issues of how achievement is evaluated along with how objectives are 
determined together constitute the overriding factor of degree of learner control, and learner control is the crux of whether a learning experience is andragogical or not. Achievement, more so than satisfaction, is the sine qua non of any examination of andragogy's effectiveness when content must be mastered and that mastery is reported in some grade, certification, or credential. (When the goal is self-fulfillment rather than content mastery, and when a grade, certification, or credential is not involved, learner satisfaction is paramount.) The question then becomes "what types of assessment fall within the boundaries of andragogy?" Clearly performance activities are closer to its spirit than paper-pencil tests, especially where the achievement, such as lumbar strength in the Cross (1989) study, is the natural outcome of the learning experience rather than a dreaded day of reckoning. This is a very high standard for the andragogy researcher, one that is difficult to implement in those classroom settings focusing more on cognitive than on affective or psychomotor learning.

A final customization of several of these studies had to do with the concept of voluntarism. As with the issues of determining objectives and determining evaluation procedures, where mutuality and collaboration can cause apparent instructor/learner role dichotomies to get fuzzy, voluntarism can also be more of a continuous variable than a dichotomous one. Andragogy is partially premised on the assumption of voluntary participation in the learning experience. Only two studies violated this principle by using andragogy in an explicitly mandated setting: White (1989) in a legislatively-mandated pesticide recertification program, and Cartor (1991) in a government training program. But there are degrees of being voluntary; one might immediately raise the question of whether any required course within an undergraduate curriculum is undertaken "voluntarily." It is certainly voluntary in that the student is not required to pursue that particular degree or go to college at all. It is further voluntary in the sense that the learner has made a prior decision to enter a program, course, or activity, knowing that after entry there will be required elements. But it is not quite voluntary in the sense of Lindeman's (1926b) The Meaning of Adult Education, or Houle's (1961) subjects in The Inquiring Mind, or adults attending a community lecture series, or participation in a noncredit class like "How to Buy and Sell a Home." Anaemena'(1986), Clark (1991), Farrar (1991), French (1984), Huntley (1985), Langston (1990), McMasters (1996), Stevens (1986), and Strawbridge (1995) all used students in higher education settings, while Beder and Carrea (1988), Cross (1989), Familoni (1992), Ogles (1990), Rosenblum and Darkenwald (1983), and White (1989) did not. Historically, undergraduate education, both because of its youthful population and because it has been seen as an extension of schooling and its attendant requirements, has not been considered adult education, though adult education may take place within it. Demographic changes in undergraduate enrollments, particularly in community colleges, may well be modifying the age-based former crisp line of demarcation between undergraduate and adult education, and in so doing allowed many of the college-based studies to utilize adults. But adults, both undergraduate and graduate, 
face "requirements" in their curricula just as 18-year-olds do. To the extent that they do, the experience is less andragogical than a purist might wish.

As earlier suggested, Knowles clearly recognized the purity issue and the consequent continuum from an imperfect implementation of andragogy necessitated by contextual constraints at one pole (such as stronger facilitator input on objectives or the necessity to give grades) to an idealized implementation of andragogy at the other (allowed by a truly volunteer adult learner motivated to pursue objectives of her or his own choosing, unconstrained by grades, prescriptive content, or other external requirements). The already noted diminished degree of freedom in the learner's selection of objectives in Knowles' foundations course as compared to his seminar course reflects this. Further, the change in the subtitle of the 1970 The Modern Practice of Adult Education ("Andragogy vs. Pedagogy") and the 1980 Modern Practice ("From Pedagogy to Andragogy") reflects his evolving view of andragogy as a continuum. But the compact definition of andragogy as "the art and science of helping adults learn" is not particularly useful as a basis for empirical examination. Even a more detailed (if also more verbose) definition of andragogy as "both a philosophy and a method of adult education in which the learner is perceived to be a mature, motivated, voluntary, and equal participant in a learning relationship with a facilitator whose role is to aid the learner in the achievement of his or her primarily self-determined learning objectives" (the author's definition) falls short for purposes of empirical testing. So is this theory, which has loomed so large in the field for three decades, impervious to meaningful empirical examination?

Obviously, the authors of the previous studies did not think so. But their varied customizations, contexts, designs, and means of implementation yield a wide range of responses to an almost as wide range of questions. Collectively, they represent important steps in a process to examine the validity of the field's central and most long-standing theory. They also provide directions for future and possibly more clarifying research - directions both to follow and to avoid. Based on those studies, we should be able to infer certain standards for the design of future research. The following are offered, all the while recognizing that mathematics-like precision is a holy grail quest.

\section{SEVEN PROFFERED CRITERIA}

1. Voluntary participation. The andragogy researcher should examine or design learning situations in which the learner wants to participate for her own personal fulfillment or some other internal motivator. In the spirit of Lindeman (1926b), this would not include professional advancement, but Knowles (1984) would accept professional advancement if it is not mandated or in any way coercive. Under no circumstances should externally imposed negative consequences follow for nonparticipation. A crystal ideal might suggest that the reward of participation would not be some material benefit, like advancement to a higher occupational 
level, but rather a totally nonmaterial benefit. But to restrict "voluntary" to the idea that the only legitimate benefit of andragogy would be learning for its own sake or self-actualization seems an excessive limitation. It also goes beyond what Knowles himself (1984, p. 12) advocated: "Although it acknowledges that adults will respond to some external motivators-a better job, a salary increase, and the like-the andragogical model predicates that the more potent motivators are internal-self-esteem, recognition, better quality of life, greater self-confidence, self-actualization, and the like." Omitting college-setting studies, where some degree of involuntarism in the learning activity can probably be assumed, only Beder and Carrea (1988), Cross (1989), Familoni (1992), Ogles (1990), Rosenblum and Darkenwald (1983), and Saxe (1987) used subjects who clearly chose to participate in the educational program. Even in these studies, motives were not necessarily "internal"; for example, Beder and Carrea paid their subjects. Future andragogy researchers would do well to examine situations such as noncredit continuing education programs where the great majority of the learners want to be there, are motivated to learn the material because it is intrinsically interesting or useful to them, and are inclined to see the learning activity as inherently valuable and not solely valuable as a means to some end.

2. Adult status. Rather than mixing adult and traditional students as Anaemena (1986), Clark (1991), Huntley (1985), Langston (1990), McMasters (1996), and Strawbridge (1995) do, future andragogy studies should avoid college settings if the various groups being compared are partly comprised of traditional college students. That is, in keeping with Knowles' view that andragogy is for adults, traditional and adult students should not be mixed within a comparison group. If a college setting is used, and traditional students are part of the study, it is very desirable to have four groups, including an adult andragogy and an adult pedagogy group. It is not desirable to have two groups where one combined group of adults and traditional students receives an andragogical treatment and a second combined group of adults and traditional students receives a pedagogical treatment, even when the adults are separated in the analysis. Although higher education settings are popular and convenient for andragogy studies, the problem can be avoided altogether by restricting future studies to settings that are exclusively adult. So what is an adult? For future andragogy research, "adult" should refer to learners who have assumed the social and culturally-defined roles characteristic of adulthood and who perceive themselves to be adult, or, if those qualities are not ascertainable, learners who have achieved an age, such as 25 , which would be regarded as adult irrelevant of social circumstances. These two criteria for adulthood accord well with Merriam and Brockett's (1997, p. 9) definition of adult education as "activities intentionally engaged in for the purpose of bringing about learning among those whose age, social roles, or self-perception define them as adults." 
3. Collaboratively-determined objectives. The andragogy researcher should examine or design learning situations in which the learner plays a significant or even primary role in the determination of the learning objectives. The use of a contract may, but does not necessarily, achieve this purpose. A contract with predetermined objectives prescribed by the instructor does not achieve this purpose unless the learner knows those objectives beforehand and they are what attracted the learner in the first place-a course, for example, on "How to plan your retirement." In such a case, what the learner wants-his/her objectives-and the course's objectives are happily congruent, and that is why the learner enrolled. When that is not the case, the andragogy researcher requires a situation in which the learner and the facilitator/instructor collaboratively negotiate what the learner wants and what the facilitator (and possibly the organization supporting the facilitator) believes is necessary to exhibit competence. Langston (1990), Madriz (1987), Ogles (1990), and Rosenblum and Darkenwald (1983) met this standard with at least one of their comparison groups. Where competence is less the goal than learner satisfaction with the experience (a book discussion group, for example), the objectives may be entirely defined by the learner(s). Andragogy researchers should seek settings in which the learner has a substantive role in some significant aspect of planning the activity or in which there is a clear, high, and pre-existing congruence between the instructor's and the learner's objectives.

4. Performance-based assessment of achievement. When the purpose of the andragogical learning experience is primarily proficiency or competence in a content area, the andragogy researcher must examine achievement. As a general guideline, the measure of achievement should be as unlike traditional schooling and as low-threat as possible. Knowles' use of a contract with a portfolio of evidence demonstrating achievement of mutually derived objectives is well known. The evidence, the criteria, and the means for evaluating that evidence are mutually agreed on by learner and facilitator. The desirable assessment measure is demonstration of the ability to perform the learned material through a direct means, such as actually taking and printing a photograph, rather than an indirect means, such as taking a paper-pencil test on how to take and print a photograph. Of those studies examining achievement, Clark (1991), Cross (1989), Huntley (1985), and Stevens (1986) utilized some performance activity as a measure of achievement. The ideal would be a performance assessment in which the performance is either clearly successful or not successful, and where the learner's very purpose in pursuing the learning activity is to exhibit a specific desired outcome. An example would be the adult learner seeking to become minimally computer-competent, and wanting to be able to send and receive an e-mail with an attachment; it either works or it does not. Essentially, this kind of performance evaluation is the distinction between Kirkpatrick's (1996) "learning evaluation," where one acquires a kind of "book knowledge" often determined through a paper-pencil test (can the learner pass a written test on how to operate the lathe correctly?), and "behavior evaluation," determined by observation of 
the learner's ability to apply or perform the learning (does the learner operate the lathe correctly?). About such "performance tests," Knowles (1980, p. 213) offers no criticism. But of "standardized tests," he is wary, noting that such "tests often smack of childhood schooling to adult learners, and so should be used with caution and preferably with the participants' full participation in the decision, administration and analysis." Slightly more acceptable to him are "tailor-made tests." But when they are prepared by the instructor and used "to compare one student to another for the purpose of giving grades to the students," they are being used in "an anti-andragogical way," and this, after all, is in fact the way they are usually used. Rather Knowles would have them used for the "students' own edification regarding relative gains," preferably "having the students construct their own tests, either for themselves or their fellow students, either individually or in teams" (p. 213). The andragogy researcher may find, however, that some types of learning content, such as learning an observable skill, may lend themselves more to performance evaluation than a content such as history or mathematics. In such cases, the researcher may possibly use a test where, as Knowles suggests, a large pool of questions is determined by the learners. An alternative might be for the researcher to have the test taken anonymously, using only group data, and only for the purpose of examining achievement as it relates to experimentally testing the andragogical methodology. This would diminish the schooling and anxiety factors Knowles finds incompatible with andragogy. Another testing alternative which would be useful in a nongraded, learning-for-its-own-sake situation would be a measure of perceived achievement such as a self-report questionnaire relative to the objectives. As a standard for assessing andragogy's effectiveness in terms of achievement (as opposed to satisfaction), these two forms of paper-pencil tests might be acceptable to the researcher. Of course, performance testing can be anxiety-producing as well as paper-pencil testing. But performance assessments, especially where what is performed is precisely the ability the learner sought in undertaking the learning experience, or at least performance tests with learner input (such as in the use of a learning contract), are more "real world" than paper-pencil achievement tests and would be closer to the gold standard.

5. Measuring satisfaction. Many adult education activities do not have as their objective the mastery of some content or acquisition of a skill, but rather the inherent pleasure or satisfaction of participating in a learning activity. In such settings, the measurement of satisfaction is critical to the andragogy researcher. But whereas achievement need not be measured in those settings where achievement is not the primary objective, satisfaction with the learning experience should be measured in all settings. Of the 18 studies analyzed here, 8 examined the variable of satisfaction with the educational activity along with one or more other variables of interest.

6. Appropriate adult learning environment. Future andragogy studies should make every attempt to insure that both the physical and the psychological environ- 
ments are as congruent as possible with Knowlesian guidelines for adult learning settings. Knowles devotes considerable space to physical logistics such as creature comforts and room arrangement, the latter suggesting not only a physically comfortable environment but also a psychologically comfortable one where a greater sense of collaboration among learners is nurtured. Psychologically, Knowles also urges as fundamental tenets of andragogy a respect for the learner as an adult, a respect for the learner's experience, a fostering of collaborative effort, and even mutual learning of both learner and facilitator, a minimizing of anxiety, and, in general, an avoidance of the schooling experience. (Two memorable symbolic gestures were his desire that the learners-not students-call him "Malcolm," and his commentary on contracts and other papers with a green-never red-pen). From the researcher's perspective, these environmental qualities are perhaps the most difficult to quantify or standardize, that is, to establish a standard or baseline for andragogy. Again, we are closer here to the art than the science of andragogy. Such atmospheric elements are often the result of some constellation of unique characteristics of the facilitator, for example, friendliness, confidence, content knowledge, charisma, empathy, humor, expressiveness, enthusiasm, body language, fairness, respect, kindness, and understanding. Such characteristics are the Mona Lisa's smile of the educator-ineffable, usually untaught, largely unteachable. But the andragogy researcher should be able to recognize when that atmosphere-however mysteriously it interacts with those individual facilitator characteristics-is not present. And when it is not, the researcher should move on to another setting.

7. Technical issues. Tdeally, random assignment of participants should occur, but the realities of adult education research are such that in situ groups are the norm and should be considered acceptable. Secondly, the issue of whether a single facilitator conducts both treatments, as in Anaemena (1986), or separate facilitators each conduct one treatment, as in Clark (1991), is vexing. One facilitator for both treatments helps assure that personality variables do not confound the outcome since presumably the educator does not present herself as Dr. Jekyll in one setting and Ms. Hyde in another. However, a single facilitator for both treatments may exhibit some bias in favor of one treatment, or be inexperienced in one treatment. By contrast, the use of two facilitators, one for each treatment, invites inevitable differences in personality, rigor, or experience which might easily be more important than the facilitators' teaching methods when it comes to outcome measures such as achievement and especially satisfaction. If two facilitators are used, it is desirable to match them as closely as possible in terms of such qualities as experience, (including experience with their assigned or selected teaching methodology), general ability, content knowledge, and teaching evaluations. Clearly a comparison of a learner-friendly andragogue with a stern pedagogue out of Dickens is not a legitimate comparison; pedagogy, after all, does not and should not mean pedantry. Finally, other criteria appropriate to experimental and quasi-experimental research should also be 
followed: adequate numbers of participants, equal and appropriate treatment duration, informed consent, comparability of groups, and so forth.

\section{CONCLUSION}

Should adult education, by definition, be andragogical? This is the philosophical question that Knowles and his many advocates have answered in the affirmative on the premise that the very nature of the adult in a learning setting demands, with few exceptions, andragogical or at least quasi-andragogical methods. Critics such as Cross (1981) note that the assumptions Knowles makes about the adult as a learner are problematic and tend to focus on ideal situations. One might therefore ask if it is not paradoxical to advocate a more standardized definition of andragogy while recognizing the contextual nature of instructional situations. This problem justifiably may disturb those advocating that all adult education be highly andragogical. But it should not disturb those who would argue that a more standardized "universal" definition of andragogy would apply only in those situations in which andragogy would be deemed appropriate in the first place. Knowles himself recognizes the situational aspect of implementing andragogy; his 1980 subtitle to The Modern Practice, "From Pedagogy to Andragogy," suggests that there are degrees of "andragogy-ness," and that implies that the appropriateness of andragogy is situational. Situational variables might include degree of voluntariness, learner's experience of and prior knowledge of the content, the need for quality control in assessing learner outcomes, the presence or absence of institutional and professional constraints, and general course goals. Pratt (1988) is particularly insightful in discussing the situationality of andragogy's appropriateness. However, except to acknowledge its importance here, that is a separate discussion except to say that "appropriateness" presupposes the even more fundamental issue of effectiveness. Questions and decisions about whether or when adult education should be andragogical are premature if we cannot establish andragogy's effectiveness.

Yet perhaps nearly all adult educators would be sympathetic to the view that as much of the spirit of andragogy as possible should infuse adult learning situations. Unfortunately, the studies of the 1980 s and 1990 s relative to andragogy's effectiveness in both achievement and satisfaction provide mixed results and often "no significant differences" emerging from variegated methodologies, and thus reveal an unstable theoretical foundation upon which to prescribe practice. It may well be that researchers examining the effectiveness of andragogy will perpetually be stymied by its fluidity, even its amoeba-like formlessness. In that view, its art will forever be paramount, and its science forever elusive, if not fraudulent. Moreover, of the three primary determinants of effectiveness in learning-the learner's ability, the learner's motivation, and teacher/facilitator factors (such as style, ability, and methodology) - the teacher/facilitator factors may be the least consequential of the three. But if andragogy is to be science as well as art; and if it is to be more than a 
slogan, more than an evangelical shibboleth, and more than a fond illusion, it must coalesce into some form of roughly agreed-upon testable hypothesis. The most persistent and best-known theoretical construct of the field of adult education over the last three decades should be more than a beloved article of faith underlying much present practice. It should move beyond anecdote and scattershot definitions implemented in apples-and-oranges empirical studies. What is required is a more operational, criteria-based definition-such as that offered here but in any case closely following the precepts and ideals of Knowles-to which future researchers might assent in conceiving and designing their investigations.

\section{NOTES}

1. Knowles sought to portray adult education not as an extension of child and adolescent education, which he refers to as pedagogy, but rather as a philosophically and methodologically separate discipline, which should be characterized by a process that he calls andragogy. To do this, he argued that the adult learner is qualitatively different from the child or adolescent learner, and the need to understand those differences justifies a separate academic discipline and necessitates a very different approach to the learner. Thus if learning is to be effective, the adult educator must both be aware of the differences as well as implement them in his or her practice. While the terms pedagogy and andragogy suggest a dichotomy, Knowles increasingly came to see the two as end points on a continuum (a paradox he never entirely resolves, and one which provides fodder for his critics). His original four assumptions about the nature of the adult learner, which form the foundation of his theory of andragogy, had evolved into five by the time of Andragogy in Action. In that work he is careful to describe the assumptions of the andragogical model in their "pure and extreme form" (p. 9), thus recognizing that they may not always apply in every aduit education situation. In brief, these idealized assumptions are: (1) the adult learner is self-directing, needing less direction from a teacher; (2) the adult learner brings a different quality and greater volume of experience to the learning setting, which can be used as a basis for further learning; (3) the adult learner approaches the learning activity on a need-to-know basis often rooted in the developmental tasks associated with his or her adult roles; (4) because of this, the adult learner is problem- and task-centered; (5) and finally, the adult learner may be motivated by external motivators, but the "more potent" motivators are internal such as self-esteem, recognition, greater quality of life, and greater self-confidence.

2. Studies were selected using search terms such as andragogy, self-directed learning, and contract learning in the ERIC database. Reference lists and bibliographies from both the relevant studies as well as related books were also examined. Studies that were not experimental or quasi-experimental, such as expository and polemical works concerning andragogy, were not considered for specific analysis but in some cases have been cited.

\section{REFERENCES}

Anaemena, E. I. (1986). A comparison of andragogy and pedagogy as instructional methodologies toward cognitive achievement in basic electronics in technical colleges of Anambra State of Nigeria (Doctoral dissertation, University of Missouri-Columbia, 1985). Dissertation Abstracts International, 47(03), 874A.

Beder, H., \& Carrea, N. (1988). The effects of andragogical teacher training on adult students' attendance and evaluation of their teachers. Adult Education Quarterly, 38, 75-87. 
Cartor, R. A. (1991). A comparison of andragogy and pedagogy: Assessing the relationship between individual personality differences, learning styles, and training types (Doctoral dissertation, University of Tennessee, 1990). Dissertation Abstracts International, 52(03), 1760B.

Clark, J. A. (1991). Self-directed learning skills and clinical performance: A comparison of traditionally taught and learning contract-taught nursing students (Doctoral dissertation, University of Southern Mississippi, 1990). Dissertation Abstracts International, 51(07), 2236A.

Cross, D. L. (1989). The influence of self-directed learning contracts versus a passive therapy treatment in a back rehabilitation program (Doctoral dissertation, Indiana University, 1988). Dissertation Abstracts International, 50(05), 1837B.

Cross, K. P. (1981). Adults as learners. San Francisco: Jossey-Bass.

Davenport, J., \& Davenport, J. A. (1985). A chronology and analysis of the andragogy debate. Adult Education Quarterly, 35, 152-159.

Familoni, P.A. (1992). The effects of non-collaborative versus collaborative vocabulary instruction on female adult beginning readers (Doctoral dissertation, University of Pitsburgh, 1991). Dissertation Abstracts International, 52(10), 3502A.

Farrar, E. W. (1991). Effects of selected teaching strategies on the visual art products of community college students (Doctoral dissertation, Arizona State University, 1990). Dissertation Abstracts International, 52(02), 400A.

French, R. T. (1984). An exploratory and descriptive study of adults studying under two modes of instruction: Classroom teaching and individualized contract teaching (Doctoral dissertation, State University of New York at Albany, 1984). Dissertation Abstracts International, 45(01), 69A.

Hornor, N. (2001). The effectiveness of an application of some concepts from andragogical instruction as compared with traditional instruction in an introductory college algebra course (Doctoral dissertation, University of Southern Mississippi, 2001), Dissertation Abstracts International, 63(05), $1761 \mathrm{~A}$.

Houle, C. O. (1961). The inquiring mind. Madison: University of Wisconsin Press.

Huntley, D. E. (1985). The use of andragogy in personal oral hygiene education with dental hygiene students (Doctoral dissertation, Kansas State University, 1985). Dissertation Abstracts International, 46(06), $1861 \mathrm{~B}$.

Kirkpatrick, D. (1996). Great ideas revisited. Training and Development, 50(1), 54-58.

Knowles, M. S. (1968). Androgogy [sic], not pedagogy. Adult Leadership, 16, 350-352, 386.

Knowles, M. S. (1970). The modern practice of adult education: Andragogy vs, pedagogy. Chicago: Association Press/Follett.

Knowles, M. S. (1980). The modern practice of adult education: From pedagogy to andragogy. Englewood Cliffs, NJ: Cambridge.'

Knowles, M. S., \& Associates. (1984). Andragogy in action. San Francisco: Jossey-Bass.

Langston, L. C. (1990). Self-directed learning, achievement, and satisfaction (Doctoral dissertation, Texas A\&M University, 1989). Dissertation Abstracts International, 50(12), 3824A.

Lindeman, E. C. (1926a, November). Andragogik: The method of teaching adults. Workers' Education, 4,38 .

Lindeman, E. C. (1926b/1989). The meaning of adult education. Norman, OK: Oklahoma Research Center for Continuing Professional and Higher Education.

Lindeman, E. C., \& Anderson, M. (1927). Education through experience: An interpretation of the methods of the Academy of Labor, Frankfurt-am-Main, Germany, Workers' Education Research Series, Monograph No. 1. New York: Workers' Education Bureau Press.

Madriz, L. (1987). The relative effectiveness of two different approaches to in-service training of primary teachers in Venezuela (Doctoral dissertation, The Florida State University, 1987). Dissertation Abstracts International, 48 (03), 539A.

McMasters, B. L. (1996). Effects of andragogical method of instruction on engineering student performance and retention in the first year (Doctoral dissertation, University of Arkansas, 1995). Dissernation Abstracts International, 56(11), 4294A. 
Merriam, S. B., \& Brockett, R. G. (1997). The profession and practice of adult education: An introduction. San Francisco: Jossey-Bass.

Merriam, S. B., \& Caffarella, R. S. (1991). Leaming in adulthood. San Francisco: Jossey-Bass.

Ogles, M. T. (1990). The outcomes of using "learning contracts" with adult beginning readers in a oneon-one literacy program (Doctoral dissertation, University of Colorado at Boulder, 1990). Dissertation Abstracts International, 51(06), 1875A.

Pratt, D. D. (1993). Andragogy after 25 years. In S. B. Merriam (Ed.), An Update on Adult Learning Theory. New Directions for Adult and Continuing Education, 57, (pp. 15-23) San Francisco: Jossey-Bass.

Pratt, D. D. (1988). Andragogy as a relational construct. Adult Education Quarterly, 38, 160-172.

Pratt, D. D., \& Associates. (1998). Five perspectives on teaching in adult and higher education: Malabar, FL: Krieger.

Rosenblum, S., \& Darkenwald, G. (1983). Effects of adult learner participation in course planning on achievement and satisfaction. Adult Education Quarterly, 33, 147-153.

Savicevic, D. M. (1999). Adult education: From practice to theory building. Frankfurt, Germany: Peter Lang.

Saxe, S. (1987). The effect of peer interaction and incentive on adult learner achievement (Doctoral dissertation, University of San Francisco, 1986) Dissertation Abstracts International, 47(07), 2421A.

Stevens, M. M. (1986). Oral hygiene instruction: Assessment of andragogical and pedagogical methods of adult patient instruction (Doctoral dissertation, Kansas State University, 1985). Dissertation Abstracts International, 46(09), 2576A.

Stewart, D. W. (1987). Adult learning in America: Eduard Lindeman and his agenda for lifelong education. Malabar, FL: Krieger.

Strawbridge, W. G. (1995). The effectiveness of andragogical instruction as compared with traditional instruction in introductory philosophy courses (Doctoral dissertation, University of Southern Mississippi, 1994). Dissertation Abstracts International, 55(11), 3387A.

White, B. A. (1989). Selected instructional strategies, learner outcome, and attitudes of adult learners in a mandatory education setting (Doctoral dissertation, Montana State University, 188). Dissertation Abstracts International, 49(08), 2074A. 